\title{
Study on the Management of Intellectual Capital
}

\author{
Yongliang Ding and Guanzhong Li \\ Industrial and Commercial College, Tianjin Polytechnic University \\ Tianjin 300387, China \\ E-mail: yong4445566@163.com
}

\begin{abstract}
In the time of knowledge economy, the Intellectual Capital gradually replaces the real capital and changes to the headspring of value enhancement for modern enterprises. To acquire advantages in the market competition, modern enterprises should not only innovate upon products, marketing channels, market and services, but also enhance the research and development ability of market and product, and specially pay attention to the cultivation and management the enterprise Intellectual Capital.
\end{abstract}

Keywords: Intellectual Capital, Management, Knowledge

When human being enters into the time of knowledge economy, the Intellectual Capital gradually replaces the real capital and changes to the headspring of value enhancement for modern enterprises. In 1990s, the proportion of Intellectual Capital in the total asset of manufacturing of Japan, US and Germany gradually ascended, and the proportion of Intellectual Capital of Japan had ascended from 10.5\% in 1990 to $14.5 \%$ in 2001, and this number of US had ascended from $30.6 \%$ to $46.9 \%$, and this number of Germany had ascended from $15 \%$ to $30.7 \%$ at the same term. In addition, some literatures recoded the Intellectual Capital of many American high-technology enterprises had exceeded $70 \%$ of their total assets. Thus, the importance of Intellectual Capital management is indubitable, and how to effectively manage the Intellectual Capital has been the hot and difficult problem in the management theory circle.

\section{Definition and Content of Intellectual Capital}

\subsection{Definition of Intellectual Capital}

The research about the definition of Intellectual Capital came of the west. The concept of Intellectual Capital was first proposed by famous economist of US, James K. Galbraith in 1969. And he thought that Intellectual Capital was not only a kind of static intangible asset in itself, but a kind of dynamic capital without fixed capital form, and it is the process effectively utilizing knowledge, and a kind of measure to realize the target. Stuart defined the Intellectual Capital as the matters which were known by all members in the company and could help the enterprise to acquire the competitive advantage in the market. And he thought that the content of capital knowledge included human capital, structural capital and customer capital. Starting from the measurement of Intellectual Capital, Advinsson and Marlon defined the Intellectual Capital as the part that the market value of the enterprise exceeded the book value. Sveiby thought that the Intellectual Capital was a kind of intangible asset based on relatively infinite knowledge.

For the research about Intellectual Capital, domestic scholars have introduced many western literatures and made many works, and based on that, some opinions have been formed. Yan Ruosen pointed out that the essential of the enterprise Intellectual Capital was to integrate intangible assets existing in organization structure, system arrangement, enterprise culture, employee's quality and enterprise management relationship. But Bai Lianzhi thought that the Intellectual Capital meant that knowledge or knowledge commodity was regarded as the measure to implement value enhancement or offer service in the knowledge economy. And Yuan Li thought that the connotation of Intellectual Capital could be defined from four aspects such as the definition, the representation, the function and the character of Intellectual Capital.

In above research results, Stuart's definition about the Intellectual Capital is agreed in this article, i.e. the Intellectual Capital is the matters which are known by all members in the company and could help the enterprise to acquire the competitive advantage in the market.

\subsection{Content of Intellectual Capital}

Stuart proposed the H-S-C structure of Intellectual Capital, and he thought that the content of Intellectual Capital should include human capital, structural capital and customer capital. Customer capital means the management assets such as marketing channel, customer loyalty and enterprise reputation. Human capital includes various skills and knowledge possessed by employees for the sustainable development of the enterprise, and they are the important base of enterprise 
Intellectual Capital. Structural capital includes the organization structure, the system standards and the organizational culture of the enterprise. Advinsson and Sullivan's opinion is different with Stuart's, and they thought that the Intellectual Capital should include human resource and structural capital. Human recourse includes all factors about human being in the enterprise, and it comes down to owner, employee, supplier and other persons who can bring their ability, knack and skills to the enterprise. Structural capital means all other abilities which don't leech on to the human resource in the enterprise. For the composing of Intellectual Capital, Stuart's opinion is agreed in this article, i.e. the content of Intellectual Capital should include human capital, structural capital and customer capital.

\section{Management of Intellectual Capital}

The important content of Intellectual Capital management is heterogeneous resource, i.e. the knowledge. The knowledge management is the core of the Intellectual Capital management, and the transfer, the flow, the sharing and the communication with the exterior in the organization all are very important to enhance the Intellectual Capital, but the Intellectual Capital management is not only to manage knowledge, but to manage the expansion of knowledge management expansion, i.e. to manage the expansion, value-enhancement and value evaluation of Intellectual Capital.

The Intellectual Capital management should include three layers as follows.

(1) The core layer. On this layer, the knowledge management could provide the knowledge platform for the expansion of Intellectual Capital by assimilating exterior knowledge, integrating interior knowledge and creating new knowledge.

(2) The expansion layer. On this layer, the enterprise Intellectual Capital could realize the value enhancement by the expansion, and accordingly drive the value enhancement of the whole enterprise.

(3) The strategy layer. As a subsystem of the enterprise management, the management of enterprise Intellectual Capital must accord with the development strategy of the enterprise and make proper adjustment according to the strategy of the enterprise.

As viewed from the content of Intellectual Capital management, it is different with other traditional managements, and the differences are mainly embodied in following aspects.

(1) Differing with knowledge management. As viewed from the object of management, the knowledge management is to mange knowledge, but the Intellectual Capital is to manage the knowledge that has been converted to capitals. Knowledge management is the base of Intellectual Capital management. For the organizations such as country and enterprise, if knowledge could not been converted into the resources which can not been invested in production (capitals), the actual meaning of management will be lost.

(2) Differing with information management. Except for managing the explicit knowledge in the enterprise knowledge resource, the Intellectual Capital management is mainly to manage the implicit knowledge of enterprise, and stimulate employees to contribute and share their accumulated implicit knowledge, which is the key for the enterprise development in the time of knowledge economy.

(3) Differing with asset management. The object of Intellectual Capital management is the intangible Intellectual Capital of enterprise. In the day when the knowledge asset is more and more important, the Intellectual Capital management is more and more practical.

(4) Influence on financial management. In the implementation of the Intellectual Capital management system, the index control of financial management is assumed by the interior knowledge network of the enterprise, and the superior layer of the enterprise could acquire relative financial data (including traditional accountant data and Intellectual Capital data), know the new trends and make decisions in time.

(5) Influence on production management. The knowledge sharing platform established by the Intellectual Capital management could effectively harmony the efficiencies of various parts and employees will actively participate in the decisions of the production management system.

(6) Influence on marketing management. The Intellectual Capital management could weaken the boundaries between the enterprise and the exterior environment, and consumers and dealers are not to passively accept the product supply of the enterprise, but participate in the marketing decisions of the enterprise, and enterprise will more approach to the market and consumers, so the enterprise will largely adopt the marketing measure (such as E-business) giving priority to network.

Intellectual Capital management will bring many benefits to one enterprise, such as reducing the time from development to application, saving costs and investments, or recycling structure capital and organization capital, and producing higher added value because of the improvement of mutual functions, and creating new values by new association and new combination.

Therefore, the Intellectual Capital management can be defined as the management of the expansion, enhancement and value evaluation of knowledge management, taking the knowledge management as the core, taking the enhancement of 
enterprise value as the intention under the condition adapting with the development strategy of the enterprise.

\section{Management Measures of Intellectual Capital}

If enterprises want to acquire advantages in the market competition, they should not only innovate upon products, marketing channel, market and service, but enhance the R\&D ability of market and product, and specially pay attention to the cultivation and management of enterprise Intellectual Capital. The target of Intellectual Capital management is to distinguish, acquire, utilize and circle Intellectual Capitals to enhance the value production ability of the enterprise.

\subsection{Strengthening the management of enterprise knowledge resources}

The knowledge resource of the enterprise means the resources which can be utilized repeatedly by the enterprise, are based on the information and technology, and bring wealth growth for the enterprise. It generally includes three aspects, i.e. the intangible assets created and possessed by the enterprise (such as brand, reputation, channel, technical flow, management mode and method, information network), information resource (various information about enterprise management acquired by the information network), intelligence resource (various knowledge which can be utilized by the enterprise and exist in human resources of the enterprise, and ability which can utilize knowledge in a creative way). It is obvious that the knowledge resource could create large market opportunity and wealth for the enterprise. Because the role of knowledge resource in the survival and development of the enterprise is more and more important, and the management of knowledge resource has turned into the most important content of the enterprise management, and the management of knowledge resource is a kind of comprehensive management, and it comes down to many domains such as human resource management, production management, marketing management, intellectual property protection, establishment of public relations, technology and information management. The intention of knowledge resource management is to offer new technology, method and environment to harmonize, support laborers' creation, distribution and utilization of knowledge, and finally enhance the core competitive ability of the enterprise. The main content of knowledge resource management generally include following aspects, i.e. the organization system and operation standards of generating, utilizing and transferring knowledge resources of enterprise, the investment management of knowledge resources such as the training of human resources, the introduction of information and technology, and the establishment of enterprise image, the establishment of the knowledge repository to improve the sharing of knowledge, the improvement of knowledge innovation to integrate creationary knowledge into products, services and production process, the protection of intellectual property, the output assessment, income distribution, confirmation and evaluation of knowledge resources.

\subsection{Strengthening the interior management and the exterior management of enterprise knowledge}

As viewed from the range of knowledge management, the knowledge management comes down to the interior management and the exterior management of knowledge. The interior management of knowledge includes the generation, communication, accumulation and application of knowledge in the interior of the enterprise. The interior management of enterprise knowledge should build a loose environment which is propitious to generate, communicate with and validate knowledge for employees, establish an information network in the interior of the enterprise convenient for employees to communicate with knowledge, constitute various encouragement polices for the knowledge communication among employees, utilize various knowledge database and patent database to store and accumulate knowledge, loosen the control of knowledge application and encourage employees to carve out their own careers in the interior of the enterprise and promote the application of knowledge. The intention of the exterior management of knowledge is to effectively manage knowledge by the communication and the cooperation among enterprise, and accumulate more knowledge for the enterprise and acquire more benefits. The exterior management of knowledge should make the enterprise to effectively communicate and share knowledge with other enterprises, and effectively cooperate with other special exterior suppliers of knowledge, and share knowledge, develop and cultivate the market with the competitors together.

\subsection{Strengthening the management of explicit knowledge and implicit knowledge}

As viewed from the management form of knowledge, knowledge can be divided into explicit knowledge and implicit knowledge. Explicit knowledge mainly means the knowledge existing by the forms such as patents, scientific invention and special technology. And the implicit knowledge means employees' creationary knowledge and ideas, and it only exists in employees' heads, which can not be observed and understood definitely by others. At present, many technologies and methods can be used to manage explicit knowledge, for example, the explicit knowledge such as patent and special technologies which can be stored in the database, and checked and used by the computer network to share them with others. Because electric information can span the obstacles induced by duties and classes in the daily contacts, make the communications among peoples more freely, and make the communication effect more effective. Therefore, enterprises must learn to use this new information and knowledge disposal tool, and grasp the new knowledge, new information and new trends in the world, and utilize all human treasures of knowledge to quicken their development. 
Implicit knowledge exists in employees' heads, which can not be observed definitely, and each enterprise has some "knowledge self-seekers" who would not easily share their knowledge with others to maintain their special status in the enterprise. Enterprises can not deprive and capture the ideas existing in these employees' head, and it needs employees to consciously contribute the knowledge to the enterprise and share with most employees, only in this way, employee's implicit knowledge can be converted into strong productivity of the enterprise. Therefore, enterprises must effectively adjust the management mechanism of the enterprise, and form the management mechanism which can encourage employees to cooperate in innovation and share knowledge.

\subsection{Enhancing the whole quality of enterprise talent resources by educational training}

In the time of knowledge economy, the competition of talents is more drastic, and one important task of human resource management is to attract and hold excellent talents. However, strong flow willing is contrary with that, and employees in the enterprise always more pay attention to their individual growths, not the requirement of the organization. Based on that, enterprises should first pay attention to the investment of human capitals for employees, perfect the talent cultivation mechanism, and offer learning opportunities for employees to accept further education and continually enhance their skills, and make them to possess the ability to obtain employment for life. Employees' requirements for the growth of knowledge, individual and career will exceed the implementation of the organizational target. When employees feel that they are only the "senior employees" of the organization, their absolute loyalty will hardly form. Therefore, enterprises should not only offer the salary according with employees' contribution, and make them to share the wealth created by them, but also fully know employees' individual requirements and wills about their occupation development, and offer the ascending road for employees. Only when employees could clearly see their development futures in the organization, they can try their best to contribute their powers and form the relationship sharing honor or disgrace in long-term cooperation with the organization.

\subsection{Establishing reasonable distribution and encouragement system}

The distribution mechanism is the key to innovate upon the mechanism of the enterprise, and the original drive to develop the enterprise. Each breakthrough of the distribution mechanism all can encourage employees' working enthusiasm and creativity. In the time of knowledge economy, the production of the society would consume knowledge largely, and people who can accumulate more knowledge and continually create new knowledge will acquire wealth. In this instance, the distribution of social wealth will take knowledge as the axis, and the salary is mainly decided by individual knowledge and skills, more pay for more knowledge.

\section{References}

Ge, Jiashu \& Du, Xingqiang. (2001). Colorful Mode of Human Resource Accounting and the Disclosure of Human Resource Information (First). Communication of Finance and Accounting. No.11, P.5-7.

Li, Guanzhong \& Liu, Zhiyuan. (2007). The Industry Analysis of Chinese Intellectual Capital Efficiency of Listed Company. Inquiry into Economic Issues, No.9, P.126-129.

Zhang, Bingfa \& Wan, Weiwu. (2006). An Empirical Research on the Effects of Intellectual Capital Investment and Intellectual Capital on Business Performance. China Soft Science, No.7, P. 137-146.

Zhang, Weiying. (1996). Influencing Factors of Managerial Ownership and Effectiveness of Stimulation. Economic Theory and Economic Management, No.9, P. 12-14.

Zhang, Zongyi \& Li, Jinyong. (2005). Research on Intellectual Capital Measurement of Chinese Public Corporations. Science \& Technology Progress and Policy, No.7. P. 30-33. 